\title{
Comment
}

Neuro epidemiology

Neuroepidemiology 2012;38:250-251

DOI: $10.1159 / 000338307$

\section{Multiple Sclerosis and Amyotrophic Lateral Sclerosis: Finding and then Losing an Association}

\section{Steven M. Albert}

Department of Behavioral and Community Health Sciences, Graduate School of Public Health, University of Pittsburgh, Pittsburgh, Pa., USA

A number of lines of inquiry have suggested a potential association between multiple sclerosis (MS) and amyotrophic lateral sclerosis (ALS). For example, familial aggregation studies have found increased risk for MS in adult children when a parent is diagnosed with ALS $[1,2]$. Case reports indicate co-occurrence of MS and ALS in patients [3]. The two disorders share some pathogenic features, such as inflammation, oxidative stress, and mitochondrial dysfunction, suggesting a possible common biological pathway $[4,5]$. Finally, a neuroepidemiologic study of the distribution of MS and ALS in Sweden between 1952 and 1992 seemed to confirm the association. Across the 24 Swedish counties, average annual mortality attributed to ALS and MS in death records was significantly correlated ( $\mathrm{rho}=0.49, \mathrm{p}=0.015$ ) [6].

In this issue of Neuroepidemiology, the authors have returned to mortality in MS and ALS across Swedish counties to examine the relationship in more recent decades, 1990-2010 [7]. Surprisingly, they found no association between mean annual age- and sex-adjusted mortality for the two diseases ( $r h o=-0.05, \mathrm{p}=0.82$ ). Repeating analyses for the different decades to account for the introduction of new immunomodulating treatments for MS did not change results. The authors conclude that their study 'failed to confirm the previously shown association between the mortality from MS and ALS, respectively, in Sweden'.

Why such different findings, and what lessons should we draw from this inability to replicate prior results? It should be said right away that the authors deserve praise for seeking to replicate the prior results, which, as they admit, were unexpected and not the object of their original study. They deserve praise as well for pointing out this failure to replicate. Their candor in admitting that they cannot fully explain differences between findings from 1952-1992 and 1990-2010 is also welcome. This humility is part of good science.

Yet the authors also do not want to abandon the hypothesis: 'given the indirect measure of the disease used in the present study, mortality statistics, these data cannot be used to firmly exclude a possible association'. So the question remains: where we see MS, are we more likely to see ALS? And if ecologic studies of annual mortality do not reveal the association, what study design should we adopt for a definitive test?

Mortality statistics are not the best guide to co-occurrence of the diseases. Changing treatments for MS have altered its mortality profile. The same may be true, though to a lesser extent, for ALS. Age-period-cohort effects may also be at work, reflecting the effect of treatments, diagnostic patterns, competing mortality risk, and differences in the distribution of underlying risk factors [8]. Adequate registration of the diseases on death certificates and consistency of diagnosis will not overcome the effects of these other factors, which may obscure associations.

A more reliable guide is incidence, as the authors recognize, and, more particularly, age distributions for incidence. These data may be derived from Swedish disability compensation records, as the authors did in their earlier study of MS and Parkinson's disease [6]. The authors did not choose to reconstruct incidence in this way for ALS, though this, as challenging it may be, will likely be required for a definitive test of the association between the diseases.

A second limitation may be areal specificity. What geographic unit is most appropriate for investigating associations between neurodegenerative diseases? The county may be too gross if a common environmental exposure is implicated. Studies of environmental factors, such as industrial contamination sites, yield very different results if cases are identified within particular distances from sites or instead assessed within larger units that contain the sites. Perhaps a similar approach can be used for ecologic studies seeking to identify associations between diseases. In this case, we require finer geographic granularity that will allow us to assess the likelihood of an ALS case within a certain distance of an MS case. These kinds of studies may be feasible now with geocoding of residences and geographic information system software.

Boström et al. [7] have shown some of the limits of ecologic studies based on mortality to investigate the association between MS and ALS and direct us to consider alternative methodologies.

\section{References}

$>_{1}$ Hemminki K, Li X, Sundquist J, Hillert J, Sundquist K: Risk for multiple sclerosis in relatives and spouses of patients diagnosed with autoimmune and related conditions. Neurogenetics 2009;10:5-11.

\section{KARGER}

Fax +4161306 1234 E-Mail karger@karger.ch www.karger.com
(C) 2012 S. Karger AG, Basel

0251-5350/12/0384-0250\$38.00/0

Accessible online at: www.karger.com/ned
Steven M. Albert, $\mathrm{PhD}$

Department of Behavioral and Community Health Sciences Graduate School of Public Health, University of Pittsburgh 208 Parran Hall, 130 DeSoto Ave., Pittsburgh, PA 15261 (USA) Tel. +1 412283 8693, E-Mail smalbert@pitt.edu 
2 Etemadifar M, Abtahi SH, Akbari M, Maghzi AH: Multiple sclerosis and amyotrophic lateral sclerosis: is there a link? Mult Scler 2012, E-pub ahead of print.

-3 Li G, Esiri MM, Ansorge O, Deluca GC: Concurrent multiple sclerosis and amyotrophic lateral sclerosis: where inflammation and neurodegeneration meet? J Neuroinflammation 2012;9:20.

-4 Staines DR: Are multiple sclerosis and amyotrophic lateral sclerosis autoimmune disorders of endogenous vasoactive neuropeptides? Med Hypotheses 2008;70:413-418.

5 Yiangou Y, Facer P, Durrenberger P, Chessell IP, Naylor A, Bountra C, Banati RR, Anand P: COX-2, CB2 and P2X7-immunoreactivities are increased in activated microglial cells/macrophages of multiple sclerosis and amyotrophic lateral sclerosis spinal cord. BMC Neurol 2006;6: 12.
6 Landtblom AM, Riise T, Boiko A, Soderfeldt B: Distribution of multiple sclerosis in Sweden based on mortality and disability compensation statistics. Neuroepidemiology 2002;21:167-179.

7 Boström I, Riise T, Landtblom AM: Mortality statistics for multiple sclerosis and amyotrophic lateral sclerosis in Sweden. Neuroepidemiology 2012 ((DOI: 338031))

8 Ajdacic-Gross V, Schmid M, Tschopp A, Gutzwiller F: Birth cohort effects in neurological diseases: amyotrophic lateral sclerosis, Parkinson's disease and multiple sclerosis. Neuroepidemiology 2012;38:5663. 